\title{
A Drawing Forged in Two and Three Dimensions
}

\author{
CARRIE NORMAN
}

Tulane University

Several recent exhibitions and symposia on drawing indicate that drawing's role is up for debate within the discipline. This paper locates an emerging mode of architectural production that is finding slack within the stiffness of Robin Evans' directive that architects make drawings, not buildings. "Forging drawings" is an alternative drawing practice that privileges neither the abstraction of two-dimensional representation nor the physical specificity of three-dimensional built form. Rather, forged drawings reposition the boundary between two and three dimensions as a site of invention.

This paper situates a context for the practice of forging drawings through case studies from both within and outside the discipline. One case study project, A Drawing Forged in Two and Three Dimensions, is discussed in detail. The project, designed by the author, is an original work of architecture produced for the drawing exhibition, Arakawa and Madeline Gins: Eternal Gradient, held at the Arthur Ross Architecture Gallery, at Columbia University Graduate School of Architecture, Planning and Preservation, in the spring of 2018. Collectively, these examples signal a shift in drawing's limits within architectural production, create new opportunity for representation's role in architecture, and raise questions for how drawing is discussed, practiced, and taught.

\section{DRAWING BUILDINGS}

Tell someone you are an architect, and you're likely to be asked what type of buildings you make. This assumption is understandable - chefs make meals, sculptors make sculpture, musicians make music, programmers make software-it follows that architects make buildings. But while buildings are important to architecture, an architect's labor almost always occurs separate from the making of buildings.

No one understood this division better than the late Robin Evans, who thirty years ago, summarized the indirect manner in which architects labor: "Never working directly with the object of their thought, always working at it through some intervening medium, almost always the drawing." 1 Evans' observation on the division of labor in architecture is often cited in discourse on representation and its evolving role within the discipline. From the academy to the profession, we are regularly reminded of Evans' seminal statement, "Architects do not make buildings; they make drawings of buildings." 2 A glance at both architectural education and professional practice offers ample evidence supporting Evans' claim. In school, learning to draw - inclusive of the terms and conventions attending its traditions - is among the first lessons asked of students. Students study the architectural canon through drawings as much as buildings. In professional practice, the contractual, regulatory, and legal requirements codify architectural drawings into a schedule of deliverables that constitute architects' 'instruments of service.' For architecture students and practicing architects alike, drawings remain central to architectural production-representations and speculations separate from built form.

But is the dividing line between drawing and building an immutable foundation of architecture, to be embraced and further codified? Or is it more complicated than Evans' formulation? Is there territory for architectural production that lies at the threshold between drawing and building? What happens when the abstract properties of drawing are directly applied to the material world? When the abstraction of two-dimensional representation collides with physical, three-dimensional building?

Several recent exhibitions and symposia on drawing indicate that drawing's role is up for debate within the discipline. ${ }^{3}$ Advancing the discipline depends on identifying codified limits, and when located, applying pressure to them. This paper locates an emerging mode of architectural production that is finding slack within the stiffness of Evans' directive. Forging drawings is an alternative drawing practice that aims to mobilize the drawing beyond an instrument subordinate to building. This paper situates a context for the practice of forging drawings through case studies from both within and outside the discipline. One case study project, A Drawing Forged in Two and Three Dimensions, is discussed in detail. The project, designed by the author, is an original work of architecture produced for the drawing exhibition Arakawa and Madeline Gins: Eternal Gradient, held at the Arthur Ross Architecture Gallery, at Columbia University Graduate School of Architecture, Planning and Preservation, in the spring of 2018.

\section{BUILDING DRAWINGS ${ }^{4}$}

To forge a drawing is to reconstitute the traditional boundaries between drawing and building. Forged drawings privilege neither the abstraction of two-dimensional representation nor the physical specificity of three-dimensional built form. Rather, forged drawings resituate the boundary between two and three dimensions as a site of invention. 


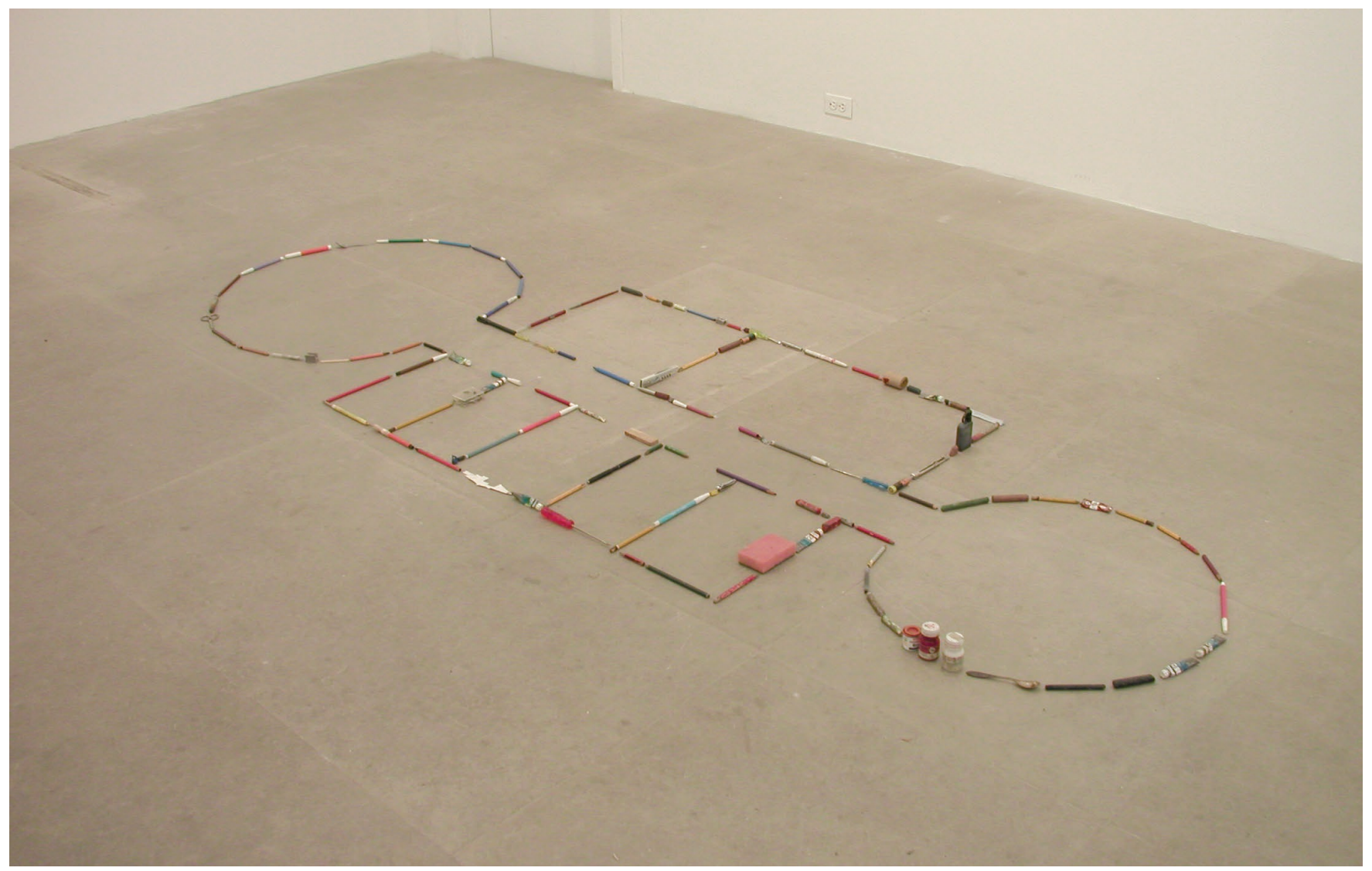

Figure 1. Mark MANDERS, Inhabited for a Survey (15-08-2007), 2005-2007, mixed media, $370 \times 220 \times 9$ cm. Courtesy of the artist, Tanya Bonakdar Gallery, New York / Los Angeles and Zeno X Gallery, Antwerp.

Formative traces of the practice can be found within undisciplined drawing 5 practices. The Dutch artist, Mark Manders (1968-), offers one example. His Inhabited for a Survey (First Floor Plan from a Self-Portrait as a Building), from 1986, introduces a suite of architectural terms for the reader, and the observer, to unscramble (figure 1). At first glance, his project reads like a plan, maybe even a familiar one. Upon closer inspection, more questions arise. Is it a shallow model? Does it have a scale? A site? Shifting attention to the title offers additional terms to sort: "first floor plan," "self-portrait," and "building." A portrait, whether drawn or painted, figural or abstract, shares conventions and standards with an architectural elevation. Both are frontal views, objects of which can be seen by an observer in physical space. A plan, on the other hand, can never been seen in totality by an observer in physical space. Rarely are the two projections - elevation (or portrait) and plan-interchangeable. Such incongruities may be of no concern to Manders, given his audience outside of architecture. His undisciplined drawing is unburdened by architecture's codified terms and their meanings.

But reading Manders' work as architecture suggests possibilities for forging drawings. Manders' work loosens the boundaries between drawing and building, between two dimensions and three. The title of his work alone is a clash of architectural conventions and terms, the incongruities of which pose questions for the role of drawing in architecture. Manders' work offers a prompt to reconsider Evans' seminal statement, and to begin to situate a practice of forging drawings by reversing the accepted sequence from drawing buildings to building drawings. A current group of architects is, to varying degrees, dabbling in this reversal, or wholly embracing it.

A practice that dabbles in forging drawings includes, for example, MOS Architects. In a number of the firm's projects, architectural graphic standard hatches are not only instruments of the drawing set, but are incorporated into the surfaces of the built work. In Chamber Gallery (New York, 2014), the graphic standard hatch pattern representing marble is CNC etched into marble shelving and pedestals that compose the project. Drawing is built, but selectively and with restraint.

Practices that engage in forging drawings wholly include, for example, FreelandBuck (David Freeland and Brennan Buck) and Mall (Jennifer Bonner). The work of these firms provokes an alternative treaty between two practices-drawing and building-whose sequence was once secure, and limits stable. 


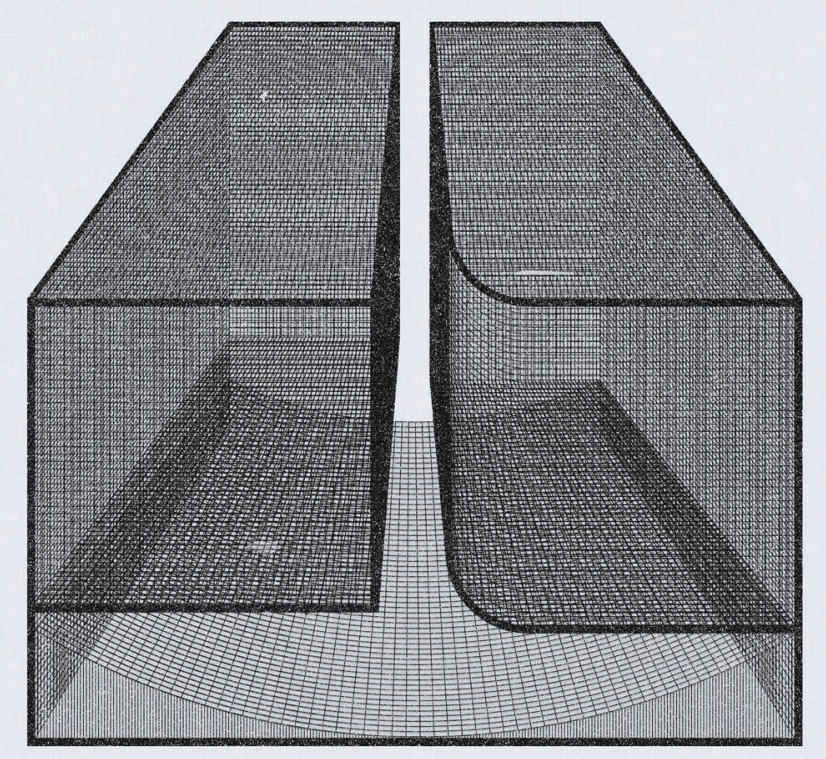

Figure 2. Arakawa/Madeline Gins, Study Landing Site - Bridge of Reversible Destiny, 1987 graphite on paper, 22 1/4 x 22 1/4 inches. Drawing by Author. To view this work, as drawn by Arakawa, see Shusaku Arakawa and Madeline H. Gins, "The Mechanism of Meaning" (New York: Abbeville Press; 2nd edition, 1988), 111. Ongoing legal disputes prohibited its reproduction in this paper.

In Parallax Gap, by FreelandBuck (Renwick Gallery, Smithsonian American Art Museum, Washington, DC, 2017), a drawing is constructed as a ceiling. The project assembles multiple perspectival illusions of American architectural domed ceilings from the 19th and 20th centuries. Composed of cut fabric on steel framing, ceiling domes are forged through planes of two-dimensional representations, to construct a continuous sequence of depth by aggregating resolution among layers. The project integrates the abstract and two-dimensional realm of representation with the physical and three-dimensional realm of tectonics.

Mall's Another Axon (Cambridge, MA, 2017) manifests another form of forged drawing. In Another Axon, the conflation between drawing and built form starts with the title, and extends to applying conventions of architectural axonometric drawing to the construction of three-dimensional space. In the project, an occupiable ground plane is composed of a series of surfaces and sculptural objects. The objects and surfaces are textured with hatch patterns that, while arranged in various orientations, foremost privilege an objective axonometric view. The objective axonometric view is then made vulnerable when subjected to imperfect viewing angles of mobile observers. The result is a forged axonometric drawing.

\section{DRAWING FORGERY}

The prompt of this panel references several recent drawingspecific events, such as Is Drawing Dead, Drawing Futures, the Drawing Show!. These events are all part of a larger conversation exploring the role and possibilities of architectural drawing. Arakawa and Madeline Gins: Eternal Gradient was an exhibition exploring similar territory, examining the boundaries of architectural drawing. The exhibition focused on hand drawings produced in the 1980's by the artist and architect Shusaku Arakawa (1936-2010), and his collaborator and wife, the poet and philosopher Madeline Gins (1941-2014). Arakawa and Gins' collaboration included drawing, painting, models, installations, poetry, literature, architecture, urbanism, and philosophy. However, the show focused on Arakawa and Gins' drawings to introduce their shift towards an intersection of human perception and spatial exploration. Irene Sunwoo, the exhibition's curator, writes in the exhibition catalog, "during the 1980s-a critical juncture in their careers - this line of inquiry became increasingly spatial as Arakawa and Gins together developed a series of speculative architectural projects that sought to challenge the bodily and psychological experience of users." Arakawa and Madeline Gins: Eternal Gradient featured the drawn experiments that preceded this built work.

The selection of work for display was led by the curator, but increasingly developed as a collaboration between curator and architect. Complications and limitations in the curation process emerged as a result of legal disputes between two foundations, each of which claimed ownership of Arakawa and Gins' body of work (the Architectural Body Research Foundation and the Reversible Destiny Foundation). ${ }^{7}$ In the late stages of the curation process, many drawings initially selected for exhibition were prohibited due to the ongoing ownership battles. The prohibited work included a drawing from one of Arakawa and Madeline's most significant projects, The Mechanism of Meaning (figure 2). Including the drawing in the exhibition required an act of architectural smuggling.

The curatorial obstacle presented an architectural opportunity to demonstrate the deceptive prowess of forging drawing. The curator and architect agreed, Arakawa's sketch had to be forged. While the practice of forgery is often in service of deception, and its product invalidating, the forging of Arakawa's sketch sought to resuscitate rather than reproduce the original (figure 3). The following criteria set the terms of forgery: First, the original must be translated into other mediums or rescaled to new dimensions, to invest reconstruction with distance sufficient to make possible ulterior readings. Second, the forged drawing must recast the value of reproduction in architectural production, in which reproduction is not an act of quotation, but an act of invention. Third, the forged drawing must be generated by a close reading of the original, regenerating the original with levels of resolution that in equal measure exceed and fall short of the original.

\section{FORGING DRAWINGS}

Arakawa's original sketch depicts three primary block masses in perspective. Two nearly identical rectangular volumes hover symmetrically above a shallow block with a concave top profile. The drawing represents the masses' surfaces 


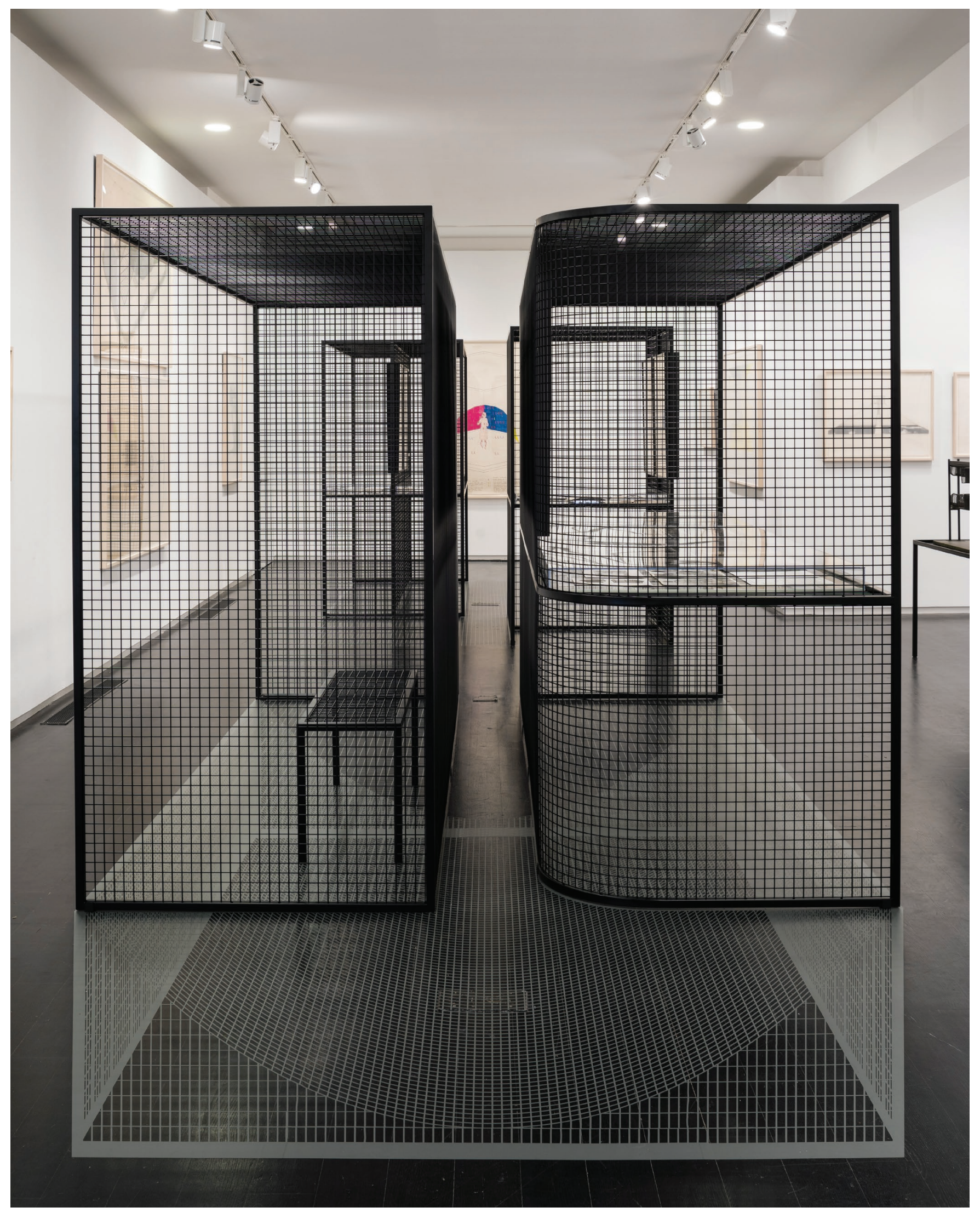




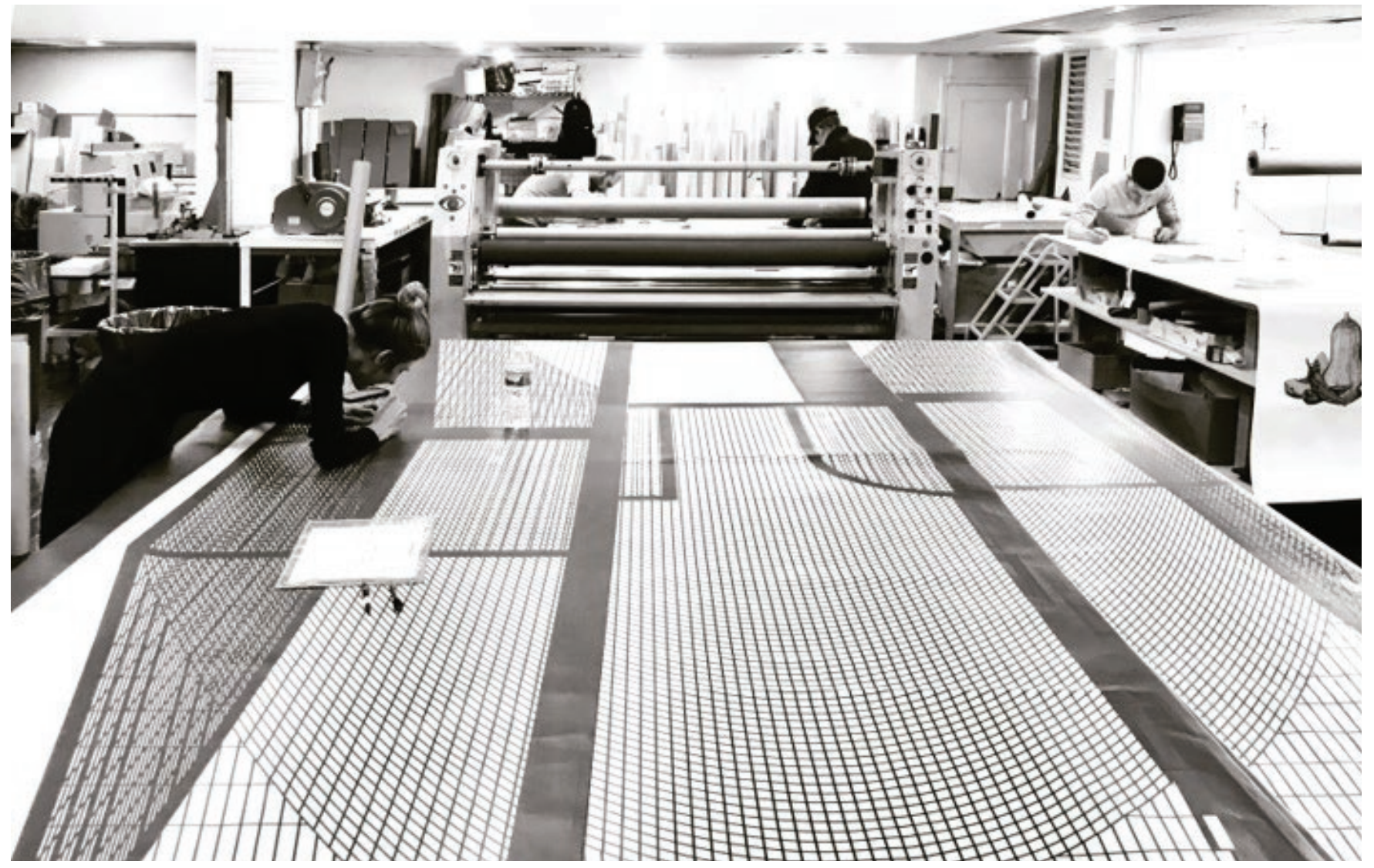

Figure 4. Process of weeding negatives from CNC cut vinyl in preparation for floor installation, New York, 2018.

with grids composed of thin lines. Apparent variation in line thickness is consistent with graphite application. Thick lines trace the masses' perimeter edges. The absence of solid fill results in a wireframe in which each surface maintains visibility. Overlapping lines resemble hatched regions, alternatingly flattening and giving depth to the masses. Arakawa describes the drawing as follows:

The container suspended on the right is one foot higher than its double. Not more than eighteen to twenty inches separate the two. To pass through this, all participants (children excepted) must walk sideways or crawl. Walls in corresponding positions differ as to mesh density from one container to the other. Six feet below the lowest point of the sloping floor, and six feet above the river, hangs a planter containing a meadow. ${ }^{8}$

The forging of Arakawa's sketch (figure 3) divides it into two parts, through a combination of two-dimensional matte gray vinyl and three-dimensional black powder coated steel structures. The upper portion of the drawing (the "containers") is forged in one-inch square tube steel and eighth-inch square wire mesh. The grid spacing of the mesh measures one inch, clear, on center, between the wires. Each container measures approximately eleven feet long, and three and a half feet wide. A twelve-inch gap separates the two. Only eyesight passes through the gap (side shimmying excepted), framing a glimpse of a large drawing on the far wall. The containers were built and installed as single monolithic units. Additional structural supports or attachment methods risked introducing 'thick lines' not present in the original. Sagging in the long direction is expected over time.

The mesh wires proportionally follow the linework present in Arakawa's sketch, but do not precisely match the density or variations in width. Exceptions occur at welded seams between the mesh panels, where the wire width doubles. Finally, Arakawa's sketch offers many possible interpretations, including whether the containers are open or closed. For exhibition purposes, the forged containers doubled as display surfaces. Arakawa and Gins' drawings, framed in black painted wood, hung equally spaced against the interior mesh panels, restricted to the container's length. Drawings inside a drawing.

The second and lower portion of Arakawa's sketch, the "slopping floor," is forged through matte gray vinyl stickers adhered to the floor of the gallery. The vinyl grid graphic approximated the proportions of Arakawa's linework, adjusted to align with spacing of the metal mesh. Drawing the floor grid relied upon as-built drawings of the steel containers. Building, then drawing. Forging the drawing revealed seams between mediums, as the material limitations of both the metal mesh and the vinyl cut sheets determined the spacing of the forged linework. 
A large-format cutting machine printed and scored three separate panels of vinyl, each measuring approximately sixteen feet long by two and a half feet wide. Vinyl is a printed material, suggesting no loss of fidelity between the digital file and the physical artifact. In practice, once printed, the vinyl undergoes a process of "weeding" in which the material is subject to meticulous manual handling. Weeding is the labor of removing unwanted material from the graphic surface. The process of weeding the vinyl was intensively three-dimensional, as technicians carefully peeled out the negatives from a perspectival grid prior to installation (figure 4). With increased handling, the material stretches, and thin lines distort. The resulting vinyl is a two-dimensional application, but subtle imprecisions in processing and applying to the floor belie its flatness.

Perceiving a seamless drawing between two and three dimensions requires work. The linework of the metal mesh and vinyl floor graphics together form an anamorphic projection approximating Arakawa's sketch. From a single vantage point, the forms and linework of Arakawa's original sketch reveal themselves to be discovered, or not, by visitors to the exhibition. This forged drawing makes a request, to delay the rush to meaning. A photo of the curator, smiling, as she searches for the sketch to become apparent proposes that drawings, like buildings, can affect physical behavior.

Forged drawings, such as the ones described in this paper, promote active viewing. In our present cultural condition, characterized by distracted attention spans and rapid image consumption, forged drawings tug at our impulse for immediate legibility. When properties of abstraction are no longer translated, but rather directly applied to the material world, idealized representation and unpredictable reality enter a wrestling match. The observer, now referee, is left with work to do. This call for heightened participation signals a shift in drawing's limits within architectural production, creates new opportunity for representation's role in architecture, and raises questions for how drawing is discussed, practiced, and taught.

\section{ENDNOTES}

1 Robin Evans, Translations from Drawing to Building and Other Essays (London: AA Publications, 1997), 156.

2 Robin Evans, "Architectural Projection," in Architecture and Its Image, eds., Eve Blau and Edward Kaufman (Montreal: Canadian Centre for Architecture, 1989), 21

3 See "Draw(ing) to a (W)hole," panel prompt.

4 The term "building drawings" can be attributed to Keith Krumwiede, used in the title of the 2016 Symposium: "Drawing Buildings, Building Drawings," held at the New Jersey Institute of Technology, Newark, NJ.

5 For further elaboration on the term "undisciplined drawing," see Alessandro Zambelli, "The Undisciplined Drawing," Buildings 3, no. 2 (2013): 357-379. http:// doi:10.3390/buildings3020357.

6 Irene Sunwoo and Tiffany Lambert, Arakawa and Madeline Gins: Eternal Gradient, Exhibition Catalogue (New York: Columbia GSAPP, 2018).

7 Sarah Douglas, "Foundation Claims Ownership of Arakawa and Gins's Sprawling 'The Mechanism of Meaning' Piece [UPDATED]," Art News, October 10, 2017. http://www.artnews.com/2017/10/10/foundation-claims-ownership-ofarakawa-and-ginss-sprawling-the-mechanism-of-meaning-piece/.

8 Shusaku Arakawa and Madeline H. Gins, The Mechanism of Meaning, second edition, (New York: Abbeville Press, 1988), 110. 